ORNLTM-12932

OAK RIDGE

NATIONAL

LABORATORY

MAETIN MARIETTA

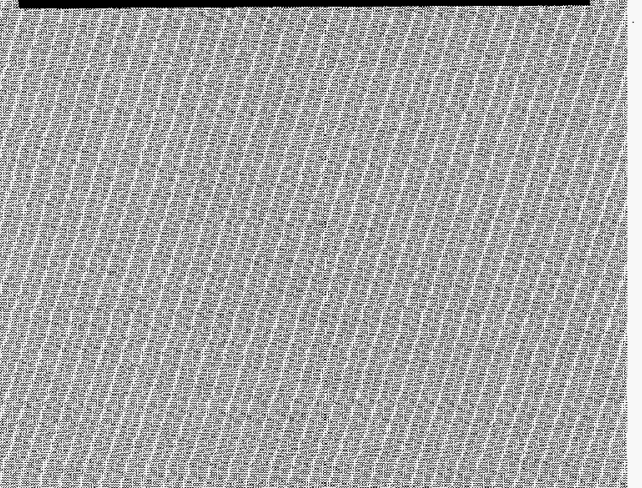

\title{
Expert Operator Preferences in Remote Manipulator Control Systems
}

\author{
Eric Sundstrom \\ John V. Draper \\ Aaron Fausz \\ Hancel Woods
}

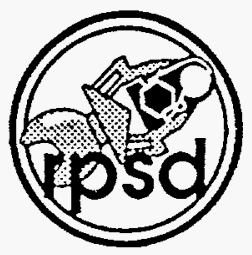

MANAGED BY

MARTIN MARIETTA ENERGY SYSTEMS, INC.

FOR THE UNITEO STATES

OEPARTMENT OF ENERGY 
This report has been reproduced directly from the best available copy.

Available to DOE and DOE contractors from the Office of Scientific and Technical Information, P.O. Box 62, Oak Ridge, TN 37831; prices available from (615) 576-8401, FTS 626-8401.

Available to the public from the National Technical Information Service, U.S. Department of Commerce, 5285 Port Royal Rd., Springfield, VA 22161.

This report was prepared as an account of work sponsored by an agency of the United States Government. Neither the United States Government nor any agency thereof, nor any of their employees, makes any warranty, express or implied, or assumes any legal liability or responsibility for the accuracy, completeness, or usefulness of any information, apparatus, product, or process disclosed, or represents that its use would not infringe privately owned rights. Reference herein to any specific commercial product, process, or service by trade name, trademark, manufacturer, or otherwise, does not necessarily constitute or imply its endorsement, recommendation, or favoring by the United States Government or any agency thereof. The views and opinions of authors expressed herein do not necessarily state or reflect those of the United States Government or any agency thereof. 


\section{DISCLAIMER}

Portions of this document may be illegible in electronic image products. Images are produced from the best available original document. 
ORNL/TM-12932

Robotics Technology Development Program

\title{
EXPERT OPERATOR PREFERENCES IN REMOTE MANIPULATOR CONTROL SYSTEMS
}

Eric Sundstrom

Human Machine Interfaces, Inc.

John V. Draper

Robotics and Process Systems Division

Aaron Fausz

Hancel Woods

The University of Tennessee

Date Published-June 1995

\author{
Prepared by the \\ OAK RIDGE NATIONAL LABORATORY \\ Oak Ridge, Tennessee 37831 \\ managed by \\ LOCKHEED MARTIN ENERGY SYSTEMS, INC. \\ for the \\ DEPARTMENT OF ENERGY \\ under contract DE-AC05-840R21400
}

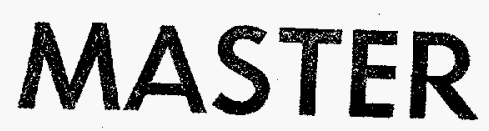

DIGTFIOUTION OF THS DOOUMENT IS UNLMITED UR 







\section{CONTENTS}

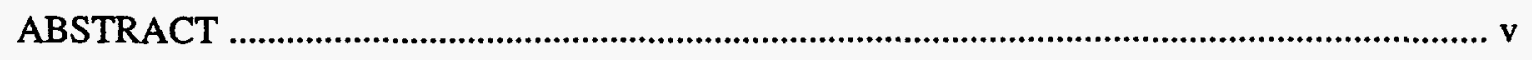

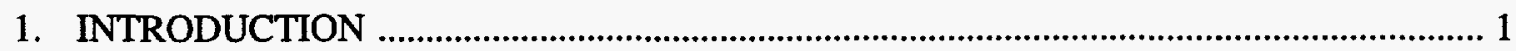

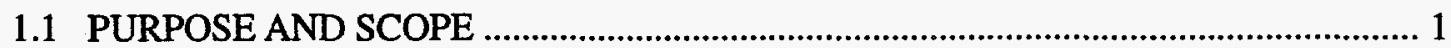

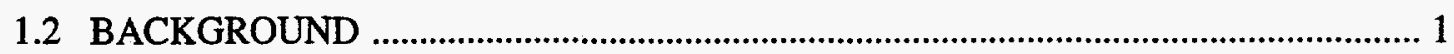

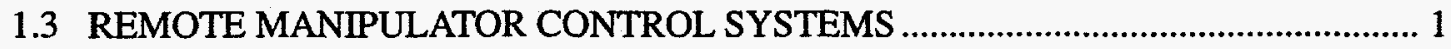

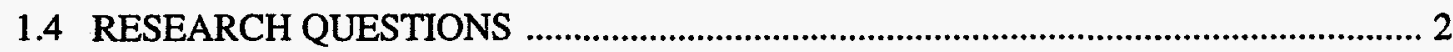

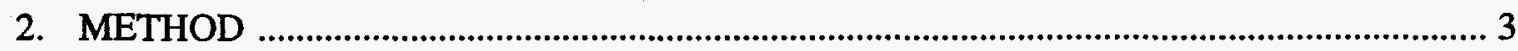

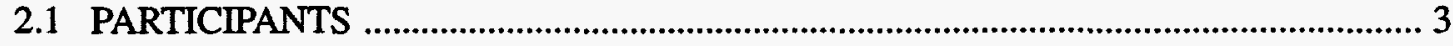

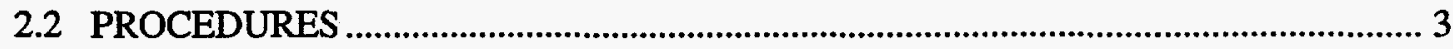



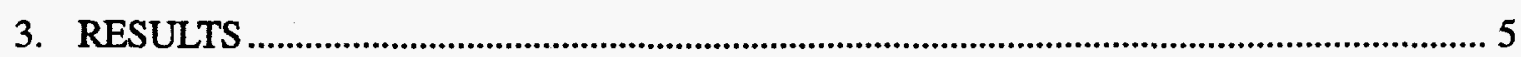

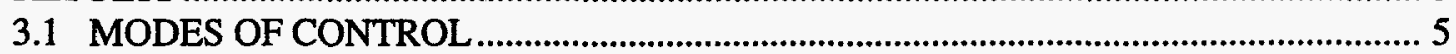

3.2 WORK SESSIONS: ACTUAL AND PREFERRED DURATIONS …............................ 5



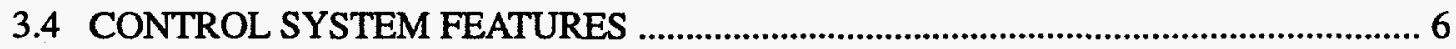

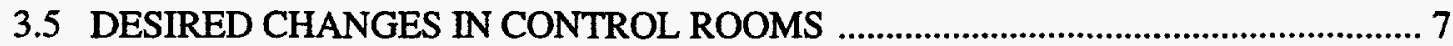



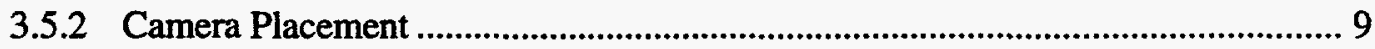

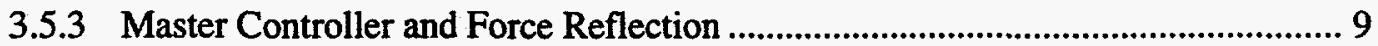





4. IMPLICATIONS FOR REMOTE MANIPULATOR CONTROL SYSTEMS ...................... 11



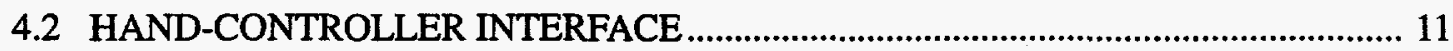



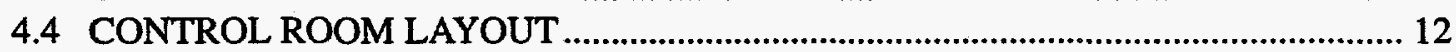

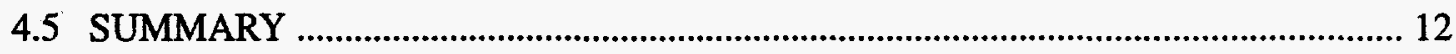

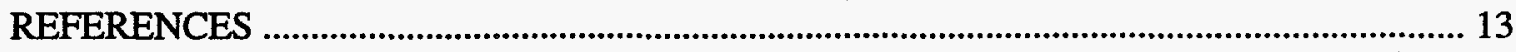




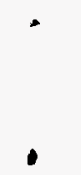

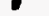

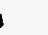




\begin{abstract}
This report describes a survey of expert remote manipulator operators designed to identify features of control systems related to operator efficiency and comfort. It provides information for designing the control center for the Single-Shell Tank Waste Retrieval Manipulator System (TWRMS) Test Bed, described in a separate report. Research questions concerned preferred modes of control, optimum work sessions, sources of operator fatigue, importance of control system design features, and desired changes in control rooms.

Participants comprised four expert remote manipulator operators at Oak Ridge National Laboratory, who individually have from 9 to 20 years of experience using teleoperators. They completed a questionnaire about their experiences and preferences concerning these systems, then participated in a group interview to clarify and expand their answers.

The operators had all used rate and position control, and all preferred bilateral (force-reflecting) position control. They reported spending an average of $2.75 \mathrm{~h}$ in control of a teleoperator system during a typical shift. All were accustomed to working in a crew of two and alternating control and support roles in 2-h rotations in an 8-h shift. Three of four operators said an optimum control session was $2 \mathrm{~h}$.

Operators reported that fatigue in using remote manipulator systems came mainly from watching TV monitors and making repetitive motions. Three of four experienced symptoms, including headaches and sore eyes, wrists, and back. Of 17 features of control rooms rated on importance, highest ratings went to comfort and support provided by the operator chair, location of controls, location of video monitors, video image clarity, types of controls, and control modes. When asked what they wanted to change, operators said work stations designed for comfort; simpler, lighter hand-controls; separate controls for each camera; better placement of remote camera; color monitors; and control room layouts that support crew interaction.

Results of this small survey reinforced the importance of ergonomic factors in remote manipulation. Operators' responses agreed with other research in pointing to the many components of the work environment important to operator efficiency and comfort.

This study suggested four design implications. First, work stations for remote manipulators need to support operator efficiency through ergonomic chairs and large color monitors in optimum viewing locations. Second, an efficient hand-control interface calls for a light, mobile hand-controller with the capacity for resolved bilateral (force-reflecting) position control and adjustable forcereflection. Third, each remote camera needs separate, dedicated controls (a departure from current practice), ideally including the capacity to adjust the location of remote cameras. Finally, the room layout needs to place operators in close enough proximity for conversation and efficient alternation of work roles.
\end{abstract}




\section{INTRODUCTION}

\subsection{PURPOSE AND SCOPE}

The purpose of this report is to describe a survey of expert operators of remote manipulator systems which was designed to identify features of control systems related to operator efficiency and comfort. The scope extends to the control of remote manipulators, systems that allow human operators to control dexterous mechanical end effectors, called "slaves," working at sites distant from the operator and the "master" controls. Also called teleoperators, they allow humans to perform tasks in hostile environments from safe locations using surrogate arms and hands which the operator controls through mechanical and electronic links while monitoring the work via remote video cameras and microphones. This report concerns the preferences of expert operators, with the intent of learning about desirable design features for the TWRMS. Specifically, the present study focused on the experiences and preferences of expert operators at the Oak Ridge National Laboratory (ORNL) concerning the teleoperator systems in their extensive experience.

\subsection{BACKGROUND}

This small survey was conducted during the design of the control center for the TWRMS Test Bed. TWRMS is in its early stages of development. Eventually, versions of the system will retrieve hazardous waste from underground storage tanks using advanced remote manipulator systems. 2,3 Components of the first test version of the TWRMS are being developed concurrently with its control center, which was designed to incorporate some of this survey's findings.

Although research on robotic systems is growing, ${ }^{4}$ relatively few empirical studies have focused on the specific ergonomic requirements of teleoperator systems. The present study provided an opportunity to capture the experience of a few members of the small population of highly experienced, expert operators of these systems.

\subsection{REMOTE MANIPULATOR CONTROL SYSTEMS}

Operators can use remote manipulator systems to perform any of five generic types of tasks: ${ }^{5}$ (1) controlling, or manually guiding a machine as it moves in real time; (2) programming, or storing behavioral sequences via symbolic instructions for machines; (3) teaching, or storing behavioral sequences via recording of controlled machine actions; (4) commanding, or eliciting programmed or taught sequences via symbolic instructions; and (5) monitoring, or observing automated behavioral sequences. In performing these tasks the operator continuously or intermittently controls the slave system. 
Remote manipulator control systems provide for eight different modes of control:5

- Digital input: Movement of the slave component is initiated by symbolic instruction (e.g., onoff switch or keyboard).

- Position control via pointing device: Slave system repertoires are selected by a cursor controller (e.g., mouse or trackball).

- Direct rate control: Displacement of the master causes the slave to move in the same direction as the master at a rate of movement determined by the amount of displacement (e.g., "joystick" controller on a backhoe). Each controller displacement axis causes motion in one slave degree of freedom.

- Resolved rate control: Displacement of the master causes the slave to move in the same direction as the master at a rate proportional to displacement, in a predetermined plane or around an axis (e.g., "joystick" controller for a jet fighter). Each controller displacement axis causes motion in one spatial axis.

- Direct unilateral position control: Slave movements mimic those of the master without force reflection; the master does not transmit forces applied to the slave; its movement does not move the master (e.g., data glove). Each slave degree of freedom is directly controlled by a single master degree of freedom.

- Resolved unilateral position control: The slave component moves with the master, in distances proportional to master displacement, resolved to specified plane(s) or around axes, without force reflection (e.g., data glove). The slave end effector mimics the user's hand trajectory.

- Direct bilateral (force-reflecting) position control: Slave movements mimic those of a master with force reflection; the slave transmits to the master forces applied to the slave (e.g., exoskeleton controller with force reflection). Each slave degree of freedom is directly controlled by a single master degree of freedom.

- Resolved bilateral (force-reflecting) position control: The slave component moves in the same direction as the master, in distances proportional to control displacement and resolved to specified plane(s) or around axes, and partially or fully transmits forces from the slave to the master.

The primary type of task done by remote manipulator systems is controlling. Research indicates that optimal modes for this type of task include resolved rate control and bilateral (forcereflecting) position control, depending on the task. 5 Applications of remote manipulators in the TWRMS facility call for dexterous manipulation, for which several remote manipulator systems at ORNL have been tested in multiple control modes, ${ }^{6,7}$ so the expert operators had extensive experience directly applicable to the design of TWRMS control systems.

\subsection{RESEARCH QUESTIONS}

Research questions focused generally on the operation of remote manipulator control systems for dexterous and gross positioning tasks, and specifically on five issues: (1) preferred modes of control, (2) optimum work sessions, (3) causes and symptoms of operator fatigue, (4) importance of specific control system features, and (5) desired changes in existing control rooms. 


\section{METHOD}

\subsection{PARTICIPANTS}

Participants consisted of four expert remote manipulator operators from ORNL. Individually they had from 9 to 20 years of experience using remote manipulator systems and an average of 15 years. All were caucasian males, ranging in age from 34 to 47 , and averaging 42 years old.

\subsection{PROCEDURES}

Participants were contacted in person and invited to complete a confidential written questionnaire on their experiences with remote manipulator systems, which took an estimated $15 \mathrm{~min}$. All agreed to do so during their regular shifts and received copies of the questionnaire. A member of the research team was available to answer questions. Afterwards the participants were invited to clarify and expand on their written answers in a prescheduled group interview which lasted over $1 \mathrm{~h}$. Two members of the research team summarized the responses to each question, asked for clarification and expansion, and summarized the responses.

\subsection{QUESTIONNAIRE}

The four-page questionnaire reproduced in the Appendix incorporated 25 items, including open-ended questions, multiple-choice questions, and structured ratings. It identified eight modes of control, asked which the operator had used, and asked for a preference. Two multipart questions on work session duration and fatigue were open-ended. A series of structured items asked for ratings of importance of 17 items in producing fatigue during an 8-h shift; ratings were made on a 5point scale: 1 = Not At All Important, 2 = Slightly Important, 3 = Moderately Important, 4 = Very Important, and $5=$ Absolutely Critical. An open-ended question asked for "five things you want most to change about control rooms." The questionnaire ended with items on demographic characteristics and included space designated for comments. 


\section{RESULTS}

\subsection{MODES OF CONTROL}

As shown in Table 1, the four participants collectively had experience with all eight modes of control, and all of the expert operators had used both direct rate control and resolved bilateral (forcereflecting) position control. When asked which mode they preferred, they all indicated that they preferred bilateral (force-reflecting) position control, because (1) they found it smoothest and most responsive and (2) it provided the best "feel" for the task. Three of four operators preferred resolved bilateral position control. One operator preferred direct bilateral position control because he viewed it as less prone to errors than other modes.

Table 1. Participants' experience with modes of control of remote manipulators

Number of

operators

Mode of control $(\mathrm{N}=4)$

Digital input 1

Position control via pointing device 3

Direct rate control 4

Resolved rate control 3

Direct unilateral position control 3

Resolved unilateral position control 3

Direct bilateral (force-reflecting) position control 2

Resolved bilateral (force-reflecting) position control

\subsection{WORK SESSIONS: ACTUALAND PREFERRED DURATIONS}

Participants reported spending from 2 to $4 \mathrm{~h}$ during a typical shift actually manipulating the master controls, an average of $2.75 \mathrm{~h}$. All four expert operators were accustomed to working in a crew of two and alternating control and support roles in 2-h rotations during the typical 8-h shift. The two most experienced operators had operated controls for as long as an entire 8-h shift; the others had manipulated the controls for only up to $2 \mathrm{~h}$ at a time. When asked how long the optimum control session was, three of four operators preferred $2 \mathrm{~h}$ on and $2 \mathrm{~h}$ off in an 8-h shift; one preferred a 1-h rotation. 


\subsection{REPORTED CAUSES AND SYMPTOMS OF FATIGUE}

When asked what caused fatigue when using a hand controller, operators said viewing TV monitors and making repeated motions. As shown in Table 2, all but one operator experienced symptoms ranging from headache to sore back after a typical work session.

Table 2. Reported causes of fatigue and symptoms after an average session

\begin{tabular}{lc}
\hline \multicolumn{1}{c}{ Reported causes and symptoms } & $\begin{array}{c}\text { Number of } \\
\text { mentions }\end{array}$ \\
\hline $\begin{array}{l}\text { Sources of fatigue } \\
\text { Viewing television monitors }\end{array}$ & 3 \\
Repeated motions & 1 \\
& \\
Symptoms experienced after an average work session & 2 \\
Headache & 2 \\
Eye strain & 2 \\
Sore wrists & 1 \\
Sore back & 1 \\
None & 2 \\
\hline
\end{tabular}

\subsection{CONTROL SYSTEM FEATURES}

When asked to rate the importance of 17 features as they relate to producing operator fatigue, the participants gave ratings ranging across the full rating scale from "not at all important" to "absolutely critical." None of the participants responded to an item that asked for a rating of "other:__ on the same scale, suggesting that the questionnaire included the important items.

Table 3 lists the features in order of their rated importance, along with the high and low rating for each. Highest ratings went to comfort and support provided by the operator chair location of video monitors video image clarity and placement of controls. Also rated important were types of controls and control modes. In the group interview the participants emphasized the importance of features of the operator chair, TV monitors, and controls in preventing or producing fatigue. 
Table 3. Control system features, listed in order of rated importance

\begin{tabular}{|c|c|c|c|}
\hline \multirow[b]{2}{*}{ Control system feature } & \multicolumn{3}{|c|}{ Operators' ratings $(N=4)$} \\
\hline & Low & High & Average \\
\hline Comfort and support provided by the operator chair & 4 & 5 & 4.25 \\
\hline Location of video monitors & 4 & 5 & 4.25 \\
\hline Clarity or sharpness of images on video monitors & 4 & 5 & 4.25 \\
\hline Placement of hand controls & 4 & 5 & 4.25 \\
\hline Type of hand controls (e.g., joystick, trackball) & 4 & 4 & 4.0 \\
\hline $\begin{array}{l}\text { Type of controller technique (e.g., position control, } \\
\text { rate control) }\end{array}$ & 3 & 4 & 3.75 \\
\hline Size of video monitors & 3 & 4 & 3.5 \\
\hline Ambidexterity of hand controls & 3 & 4 & 3.5 \\
\hline Lighting of the control room & 3 & 4 & 3.5 \\
\hline Number of video monitors & 2 & 4 & 3.25 \\
\hline $\begin{array}{l}\text { Number of functions/operations controlled } \\
\text { by a video menu }\end{array}$ & 2 & 4 & 3.25 \\
\hline Layout of menu screens & 2 & 4 & 3.0 \\
\hline Floor plan or layout of control room & 2 & 4 & 3.0 \\
\hline Color of menu screens & 2 & 3 & 2.5 \\
\hline Color and decor of control room & 1 & 4 & 2.25 \\
\hline
\end{tabular}

Ratings: 1 = Not At All Important; 2 = Slightly Important; 3 = Moderately Important; 4 = Very Important; 5 = Absolutely Critical.

\subsection{DESIRED CHANGES IN CONTROL ROOMS}

The questionnaire asked participants to name "five things you most want to change about control rooms." The largest number of changes mentioned by any one operator was four. Shown in Table 4, three issues were mentioned independently by more than one operator in answering the questionnaire: access to camera controls, remote camera placement, and smaller/lighter master controls. All of the issues in Table 4 were expanded in the group interview. 
Table 4. Things operators want most to change about control rooms

\begin{tabular}{lc}
\hline \multicolumn{1}{c}{ Control room feature } & $\begin{array}{c}\text { Number of } \\
\text { mentions }\end{array}$ \\
\hline Access to camera controls & 2 \\
Placement, location of cameras on slave system & 2 \\
Smaller, lighter master controller & 2 \\
High-resolution monitors & 1 \\
Comfort of operator station: Chair and controls & 1 \\
Closer proximity to second operator & 1 \\
Fewer controls on master & 1 \\
Add foot switch(es) & 1 \\
\hline
\end{tabular}

\subsubsection{Camera Control}

When expanding in the interview on their questionnaire responses, the operators had much to say about camera controls. They asserted that most of the information they received from the remote work area is visual, so it is extremely important to be able to quickly and easily adjust all of the cameras in the remote area. They pointed out that they spend an unnecessarily large fraction of their time sorting through graphic menus to reach the appropriate camera control to make an adjustment, and they find it frustrating for camera control to take so much time and effort. They explained that because most of their tasks require one-handed control, they prefer to be able to dedicate one hand to camera control. If they could choose, they would have separate camera controls for each camera, with dedicated controls for each function (pan, tilt, zoom, focus, iris, lights). This contrasts with current designs in which one interface controls several cameras, requiring selection through a menu system.

The operators also commented on other features of camera control. They favored having an option for automatic camera tracking of the end effector. When asked about having the support operator control the cameras, three operators said they preferred to have control of cameras themselves because it was difficult to communicate exactly what they want done with the cameras and communication would waste time. One operator preferred to have a support operator at the camera controls so he did not have to worry about them. All agreed that the best allocation of camera control depends on the task. Operators were asked at the group interview about voice control of cameras, which was used in other projects.7,8,9,10 They replied that their experience with voice control systems had been less than positive because of inconsistency in the audio systems in receiving spoken words. 


\subsubsection{Camera Placement}

The operators said that camera placement in the remote area has sometimes been an afterthought in manipulator system design, a problem that becomes apparent when the arm blocks a camera view. One operator wanted different placement of side cameras; another wanted the topview camera higher on one system (the ASM). In the interview the operators agreed that the optimum viewing angle for most tasks is downward, while most systems provide camera views from about the same height as the slave system, perhaps slightly raised. They also pointed out that the optimum camera placement and viewing angles depend on the task, so no single configuration of remote cameras will always be ideal.

\subsubsection{Master Controller and Force Reflection}

Operators had experienced some large, heavy master arms and preferred the lighter ones because they were less fatiguing to use. All preferred force reflection but wanted it adjustable. They said that force reflection is most important in the early trials of a task while "getting the feel" of a task. With experience force reflection becomes less critical and can be decreased to reduce operator fatigue. All of the expert operators wanted to be able to adjust force reflection from zero up to a ratio of 16 to 1 .

\subsubsection{Video Monitors}

In the questionnaire one operator expressed a preference for high-resolution color video, a topic that led to considerable discussion in the group interview. Some researchers argue that stereo TV (or STV) is superior to mono-image TV for teleoperators, 11 because STV provides retinal disparity cues. Others argue that mono-image TV provides sufficient depth cues from such information as shadows and size.12 Participants in this study indicated a preference for STV because it provides more information. However, they expressed a stronger and more consistent preference for color TV over black and white. Even in environments with practically no color (such as underground waste storage tanks), they said that color TV gives more visual information and causes substantially less operator fatigue.

\subsubsection{Other Issues}

All of the operators agreed on the importance of the comfort of the operator's chair. One operator pointed out that the traditional teams of two operators work best when their work stations are in close enough proximity to allow for convenient conversation; all participants agreed with this point. One mentioned that some hand controllers have too many switches, which can lead to confusion and errors and suggested that some switches can be converted to foot switches. 


\section{IMPLICATIONS FOR REMOTE MANIPULATOR CONTROL SYSTEMS}

Results of this small survey reinforced the importance of a variety of ergonomic factors in remote manipulation control systems. Operators' responses agreed with other research ${ }^{4}$ in pointing to the many components of the work environment important to operator efficiency and comfort, especially the chair, video monitors, hand controllers, and camera control interface. The survey pointed to several specific design implications for remote manipulator control systems, including the design of the work station, the camera interface, the hand control, and the layout of the control room.

\subsection{WORK STATION DESIGN}

Responses of expert operators of remote manipulator systems suggested that a control center can support operator efficiency through ergonomic chairs and large color monitors in optimum viewing locations. The emphasis on an ergonomic operator chair contrasts with the use of office chairs in some earlier systems, ${ }^{6}$ and is consistent with guidelines for work station design. ${ }^{13}$ Color television is sometimes avoided because of the greater reliability of black-and-white television. (The part most vulnerable to failure in remote viewing environments is the electron gun, of which there are three in a color camera and one in a black-and-white camera.) However, the strong preference by expert operators for color television suggests an obvious agenda for system testing.

\subsection{HAND-CONTROLLER INTERFACE}

An efficient hand-control interface calls for a light, mobile hand controller with the capacity for resolved bilateral (force-reflecting) position control and adjustable force reflection. These expert operators reinforced the consistent finding in earlier research of best overall performance in systems with force-reflecting position control. ${ }^{14}$ However, they suggested a qualification: that force reflection is most needed when the operator does a new task and is required less as the operator learns. This is important because high force-reflection ratios cause fatigue, and reducing the forcereflection load could improve operator efficiency. The expert operators' suggestion of highly adjustable force-reflection ratios represents a slight departure from current practice and a design feature well worth incorporating in future systems.

A second implication concerns the size and simplicity of hand controls: smaller, simpler, and lighter is better from the operator's perspective. Whereas current practice is to add more and more functions to a single hand controller, these operators preferred adding more controls, even foot switches. This suggests an obvious avenue of remote manipulator system testing.

\subsection{CAMERA INTERFACE}

Because of the importance and frequency of camera adjustment, the expert operators called for separate controls for each camera, with dedicated controls for each function. This suggestion represents a departure from current practice, in which a single interface serves multiple cameras. ${ }^{6}$ 
However, current technology allows a compact interface that meets the expert operators' requirements: "mini-joysticks" (small, spring-loaded return-to-center controls with 3 D.F.). A hand-sized panel with six such switches could control three remote cameras with dedicated control functions. Current technology also provides capacity to satisfy their request for computer-guided tracking of cameras to the end effector.

The operators expressed dissatisfaction with remote camera placement, for which the obvious solution is adjustable remote camera location. For example, cameras can be mounted on telescoping booms with swiveling "shoulders," allowing flexible selection of front and top camera views. This relatively inexpensive design change could add considerably to the efficiency of remote manipulation systems, both by saving time and reducing errors. Using a remote manipulator to place a camera within the remote area is also an option worth considering.

\subsection{CONTROL ROOM LAYOUT}

The expert operators expressed a preference for a room layout that places operators in close enough proximity for conversation and efficient alternation of work roles. A few earlier systems were designed explicitly with this guideline in mind, 6 though little research had specifically investigated the gains from such designs. (See Reference 15 for an example of a study that did investigate this topic).

\subsection{SUMMARY}

In brief, this small survey of expert operators suggested four design implications for remote manipulation control systems. First, work stations need to support operator efficiency through ergonomic chairs and large, color monitors in optimum viewing locations. Second, an efficient hand-control interface calls for a light, mobile hand controller with the capacity for resolved bilateral (force-reflecting) position control and adjustable force reflection. Third, each remote camera needs separate, dedicated controls (a departure from current practice), ideally including the capacity to adjust the location of remote cameras. Finally, the room layout needs to place operators in close enough proximity for conversation and efficient alternation of work roles. 


\section{REFERENCES}

1. E. Sundstrom et al., Test Bed Control Center Design Concept For Tank Waste Retrieval Manipulator Systems, ORNL/TM-12793, Martin Marietta Energy Systems, Inc., Oak Ridge Natl. Lab., in preparation.

2. S. M. Babcock et al., Single-Shell Tank Waste Retrieval Manipulator System, ORNL/TM12210, Martin Marietta Energy Systems, Inc., Oak Ridge Natl. Lab., September 1992.

3. J. V. Draper, Task Analysis for the Single-Shell Tank Waste Retrieval Manipulator System, ORNL/TM-12432, Martin Marietta Energy Systems, Inc., Oak Ridge Natl. Lab., December 1993.

4. J. V. Draper, "Teleoperators for Advanced Manufacturing: Applications and Human Factors Challenges," International Journal of Human Factors in Manufacturing. Martin Marietta Energy Systems, Inc., Oak Ridge Natl. Lab., (1994b)

5. J. V. Draper. Teleoperator Hand Controllers: A Contextual Human Factors Assessment. ORNL/TM-12762, Martin Marietta Energy Systems, Inc., Oak Ridge Natl. Lab., May 1994.

6. J. V. Draper et al., Final Report: Manipulator Comparative Testing Program. ORNL/TM10109, Martin Marietta Energy Systems, Inc., Oak Ridge Natl. Lab., 1987.

7. J. V. Draper, Manual, Voice, and Automated Control of a Teleoperator Viewing System, Unpublished Doctoral Dissertation, The University of Tennessee, Knoxville 1987.

8. A. K. Bejczy, "Sensors, Controls, and Man-Machine Interface for Advanced Teleoperation," Science, 208 (4450), 132713351980.

9. A. K. Bejczy, R. S. Dotson and F. P. Mathur, "Man-Machine Speech Interaction in a Teleoperator Environment," Proceedings of the 17th Annual Conference on Manual Control, UCLA Press, Los Angeles, CA, pp. 627-640 1980.

10. R. Frenette, Evaluation of Video Controls for Remote Manipulation, Unpublished Masters . Thesis, University of British Columbia 1985.

11. A. A. Dumbreck, C. W. Smith, and S. P. Murphy, "The Development and Evaluation of Stereoscopic Television System for Use in Nuclear Environments," Proceedings of the International Topical Meeting on Remote Systems and Robotics in Hostile Environments, American Nuclear Society, LaGrange Park, IL, pp. 106-113 1987.

12. K. A. Stevens and A. Brooks, "Integrating Stereopsis with Monocular Interpretations of Planar Surfaces," Vision Research, 28(3), 371-386 1988. 
13. E. Sundstrom, Workplaces: The Psychology of the Physical Environment in Offices and Factories, New York: Cambridge University Press, 1986.

14. J. V. Draper et al., "Effects of Force Reflection on Servomanipulator Performance" Proceedings of the American Nuclear Society International Topical Meeting on Remote Handling and Robotics in Hostile Environments, American Nuclear Society, LaGrange Park, IL, pp. 654-660 1987.

15. C. C. Hood, J. V. Draper, and S. Handel, "Activity and Cooperation in a Multi-Person Teleoperator Cockpit," Proceedings of the Human Factors Society 34th Annual Meeting, The Human Factors Society, Santa Monica, CA pp. 660-663 1990. 


\section{INTERNAL DISTRIBUTION}

1. G. A. Armstrong

2. S. M. Babcock

3. J. Baker

4. R. E. Barry

5. M. Beckerman

6. B. E. Bernacki

7. K. C. Bills

8. E. C. Bradley

9-19. B. L. Burks

20. J. B. Chesser

21-31. J. V. Draper

32. W. E. Dixon

33. R. L. Glassell

34. D. C. Haley

35. W. R. Hamel

36. S. N. Hammonds

37. J. H. Hannah

38. J. N. Herndon

39. D. H. Hwang

40. J. F. Jansen

41. J. P. Jones

42. S. M. Killough

43. H. E. Knee

44. R. L. Kress

45. C. T. Kring

46. D. S. Kwon

47. R. F. Lind

48. P. D. Lloyd

49. A. P. Malinauskas

50. R. C. Mann
51. M. W. Noakes

52. T. E. Noell

53. D. J. Nypaver

54. F. G. Pin

55. K. E. Plummer

56. P. M. Rathke

57. D. B. Reister

58. B. S. Richardson

59. J. C. Rowe

60. D. A. Schoenwald

61. S. L. Schrock

62. M. Simpson

63. J. O. Steigler

64. C. W. Summey

65. D. H. Thompson

66. H. Toy

67. M. A. Unseren

68. K. U. Vandergriff

69. J. D. White

70. A. L. Wintenberg

71. H. R. Yook

72. ORNL Central Research Library

73. ORNL Document Reference Section

74-75. ORNL Laboratory Records

76. ORNL Laboratory Records RC

77. ORNL Patent Section 


\section{EXTERNAL DISTRIBUTION}

78. Clinton Bastin, Manager, LMR Reprocessing Projects, Division of Fuels and Reprocessing, Office of Facilities, Fuel Cycle, and Test Programs, NE-471, Department of Energy, Washington, DC 20545.

79. W. R. Jaquish, Pacific Northwest Laboratories, P.O. Box 999, Richland, WA 99352.

80. M. S. Evans, Pacific Northwest Laboratories, P.O. Box 999, Richland, WA 99352.

81-131. P. Gibbons, Westinghouse Hanford Company, 2355 Stevens Drive, Building. MO-414, Richland, WA 99352

132. E. Goodman, Fusion and Nuclear Technology Branch, Energy Programs Division, Department of Energy, P.O. Box 2008, Oak Ridge, TN 37831-6269.

133. E. L. Grasz, Lawrence Livermore National Laboratory, P.O. Box 808, L-439, Livermore, CA 94550.

134. R. W. Harrigan, Sandia National Laboratories, P.O. Box 5800, Division 1414, Albuquerque, NM 87185.

135. F. B. Hazen, Fernald Environmental Restoration Management Corporation, P.O. Box 398704, MS 81-2, Cincinnati, OH 45239-8704.

136. F. Heckendorn, Westinghouse Savannah River Company, Building 773-A, D1145, Aiken, SC 29808.

137. D. Herman, Fernald Environmental Restoration Management Corporation, P.O. Box 398704, MS 81-2, Cincinnati, OH 45239-8704.

138. R. M. Hollen, Los Alamos National Laboratory, P.O. Box 1663, MS J-580, Los Alamos, NM 87545.

139. D. S. Horschel, Sandia National Laboratory, P.O. Box 5800, Division 1414, Department 1661, Albuquerque, NM 8718.

140. W. Jaquish, Westinghouse Hanford Company, LO-18, P.O. Box 1970, Richland, WA 99352.

141. L. McDaniel, Westinghouse Hanford Company, LO-18, P.O. Box 1970, Richland, WA 99352. 
142. E. Shen, Westinghouse Hanford Company, LO-18, P.O. Box 1970, Richland, WA 99352.

143. R. Singer, Westinghouse Savannah River Company, Building 773-A, D-1145, Aiken, SC 29808.

144. C. R. Ward, Westinghouse Savannah River Company, Building 773-A, D-1145, Aiken SC 29808.

145. B. M. Wilding, Westinghouse Idaho Nuclear Company, P.O. Box 4000, Idaho Falls, ID 83403-5104.

146. A. P. Williams, Westinghouse Hanford Company, LO-18, P.O. Box 1970, Richland, WA 99352.

147. L. W. Yarbrough, Department of Energy, 12800 Middlebrook Road, MS EM-55, Trevion II, Germantown, MD 20874.

148. J. Yount, Westinghouse Hanford Company, LO-18, P.O. Box 1970, Richland, WA 99352.

149. Office of Assistant Manager for Energy Research and Development, DOE Oak Ridge Field Office, P.O. Box 2008, Oak Ridge, TN 37831-6269.

150-151. Office of Scientific and Technical Information, DOE Oak Ridge Field Office, P.O. Box 62, Oak Ridge, TN 37831. 